\title{
Analysis of Removing Barnacles Attached on Rough Substrate with Cleaning Robot
}

\author{
Chao Li ${ }^{1}$, Gang Wang ${ }^{2, *} \mathbb{C}$, Kaiyun Chen ${ }^{3}$, Peng Jia ${ }^{1}$, Liquan Wang ${ }^{1}$, Xiangyu Wang ${ }^{1}$ and \\ Feihong Yun ${ }^{1}$ \\ 1 College of Mechanical and Electrical Engineering, Harbin Engineering University, Harbin 150001, China; \\ 54529880@hrbeu.edu.cn (C.L.); 13633605161@139.com (P.J.); wangliquan@hrbeu.edu.cn (L.W.); \\ wangxiangyu325@126.com(X.W.); yunfeihong@hrbeu.edu.cn (F.Y.) \\ 2 College of Shipbuilding Engineering, Harbin Engineering University, Harbin 150001, China \\ 3 College of Mechanical Engineering, Heilongjiang University of Science and Technology, \\ Harbin 150001, China; chenkaiyun@hrbeu.edu.cn \\ * Correspondence: wanggang@hrbeu.edu.cn
}

Received: 22 June 2020; Accepted: 27 July 2020; Published: 29 July 2020

check for updates

\begin{abstract}
In this paper, a cleaning robot is designed to remove the marine fouling attached to a marine steel pile. In the following study, in order to analyse the process of cleaning marine fouling attached to a rough substrate, the barnacle is taken as a typical case in order to study the horizontal cutting force in the scarping process for removing barnacles on a rough substrate. The adhesion model of the barnacle was established on a rough rigid substrate. Considering both right angle cutting theory and the Peel Zone method, a scraping means and horizontal cutting force model for rough surface cleaning are proposed for the study of the surface cleaning of steel piles. In order to make the model more accurate, the finite element method is used to analyze and compare its errors. Through comparative analysis, it is known that the relative average errors about the cutting force in the horizontal direction are less than $15 \%$. The analysis shows that the blade rake angle and rough substrate have a great influence on the horizontal cutting force. It can be concluded that the cutting force needed to clean the barnacle attached to the surface decreases correspondingly as the rake angle of the blade increases; and the rougher the substrate is, the greater the horizontal cutting force required. It is recommended to use $60^{\circ}$ for blade rake angle. We can use the model to predict the horizontal cutting force and blade rake angle in the design of a cleaning robot.
\end{abstract}

Keywords: cleaning robot; barnacle model; right angle scraping; forces analysis; rough substrate

\section{Introduction}

In recent years, with the development of offshore engineering, pile foundation has been extensively used for offshore wind mills, drilling platforms, ports, piers, etc. Most of the steel piles stand in the splash zone [1] and endure seawater corrosion as well as marine fouling [1,2]. As a result, the pile life cycle is affected severely [3], and further leads to a heavy cost in both man power and finance for maintenance [4]. Therefore, it is imperative to regularly clean steel piles and/or prevent marine fouling from accumulating on the surface of steel piles.

The anti-corrosion treatment of the steel pile surface generally includes four methods: cleaning marine fouling, applying anti-corrosion paste, wrapping up with anti-corrosion tape, and putting on protective covers [5]. Chemical, mechanical, water jet, sonic, and ultraviolet methods have been used to remove marine fouling. The chemical method involves using chemicals or biological fungicides to kill microorganisms. The chemicals are toxic to microorganisms, and the biological fungicides can destroy cell structure and function [6], but this causes water pollution [7] as well as equipment 
corrosion [8]. The mechanical method involves manually brushing the pile surface [9]. In recent years, underwater cleaning robots have been developed to brush the steel surface instead of using man power [10], but mainly for the ship hull rather than steel piles. The water jet technique has also been used for cleaning, including high pressure water jet $[11,12]$ and cavitation water jet $[13,14]$. However, this method is not able to ensure full removal of marine fouling. The high-pressure water jet method is usually equipped with pressurization equipment, thus making the overall structure more inconvenient. The acoustic method is mainly used to remove marine fouling on ship hulls [15], rather than steel piles. The ultrasonic cavitation method is used to clean marine fouling by ultrasonic-produced cavitation, but the efficiency is low and it is a kind of pollution to other organisms in the ocean nearby [16]. The ultraviolet method involves using ultraviolet to kill the biofouling [17] in seawater, but is not suitable to remove biofouling on rigid surfaces [18]. A new cleaning method is required for removing marine fouling efficiently, as well as related devices. The scraping method has not been trialled to remove marine fouling on steel piles.

Murakawa and Takeuchi [19] scraped off the diamond coating on the substrate surface and measured the cutting force to estimate the adhesion strength. Xie et al. [20,21] scraped the substrate with a scraper and measured the bonding strength of various metal films. Daitoku and Utaka [22] scraped the solid clathrate hydrate from the heat exchanger surface and examined the force required for scraping. Koji and Takahiro [23] measured the scraping force of ice on the cooling surface. Y.L. Li and M.X. Li et al. [24] measured the scraping force for removing frost on vertical cooling surfaces. The scraping means could be used to clean fouling organisms attached to steel piles, instead of killing biological cells by way chemical methods, such as bactericides. In addition, it will not cause pollution to the marine environment. In this paper, a cleaning robot with scraping tools is presented for removing marine fouling on steel piles, to take place of manual operation. Based on our previous research on the removal of barnacles by scraping method, in order to be closer to the actual situation (considering that the surface of marine steel piles is actually rough), we conducted a further study on the behavior of removing barnacles on a rough substrate with scraping tools.

Among the different kinds of marine hard-fouling, the most typical example that we choose is the barnacle, which is as a model and object for this study to support the maximum scraping force and the system power estimation.

\section{Cleaning Robot}

The purpose-built robot for the marine steel pile cleaning is as shown in Figure 1A,B. It is composed of a frame, clamps, hinges, lock, gears, and scraping tools. The frame consists of upper and lower rings and three hydraulic cylinders-hydraulic cylinder 1 and two hydraulic cylinder 2 . Both upper and lower rings are composed of two half rings, hinges, and a lock, as shown in Figure 1C. The rings can be opened, hug the steel pile, and hold the frame at a given height along the steel pile with clamps. The hinges are composed of a hinge base and two hydraulic cylinder 3, which can control the rings opening and closing. Three hydraulic cylinders 1 and 2 connect the upper and lower rings and control the distance between the rings. With loosening and locking the upper and lower rings alternatively, the robot can move up and down along the steel pile. The gears are composed of gear rings and a driven wheel. The gears connecting the scraping tools are under the upper rings, which drives the scraping tools to rotate $90^{\circ}$ around the steel pile. The scraping tools are composed of four sets of hydraulic cylinder 4, support bars, slideways. and blades. The hydraulic cylinder 4 drives the blades up and down along the steel pile at a certain angle to remove marine fouling, as shown in Figure 1D. 


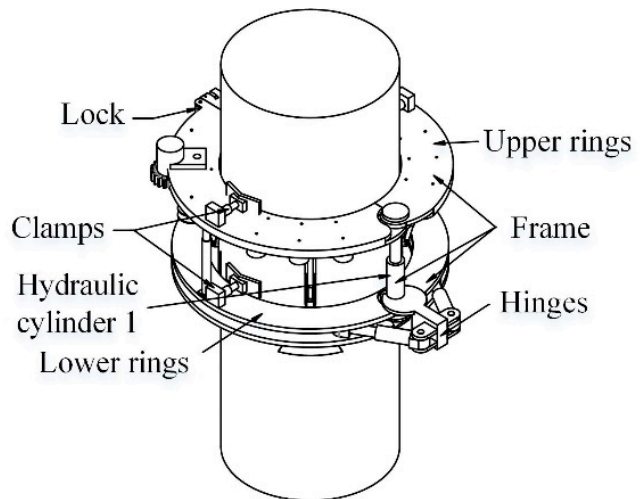

(A)

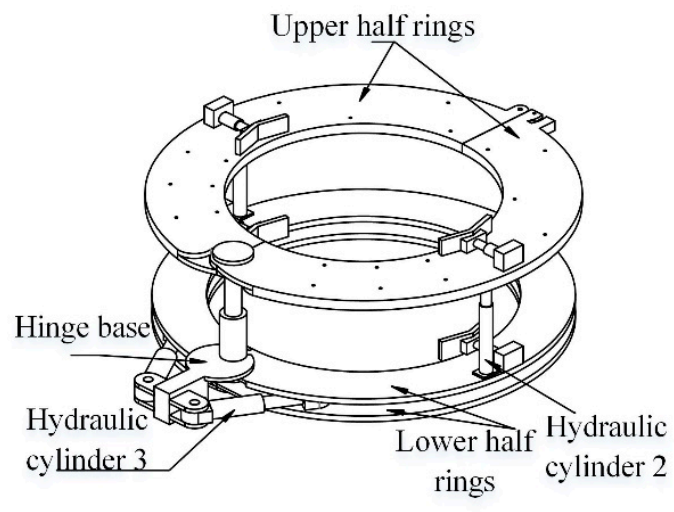

(C)

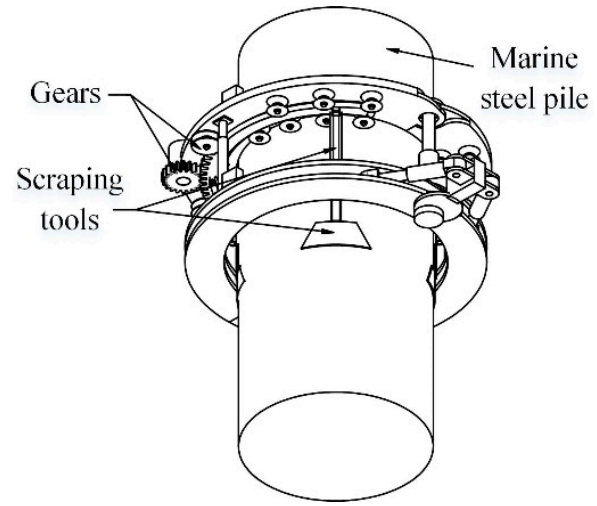

(B)

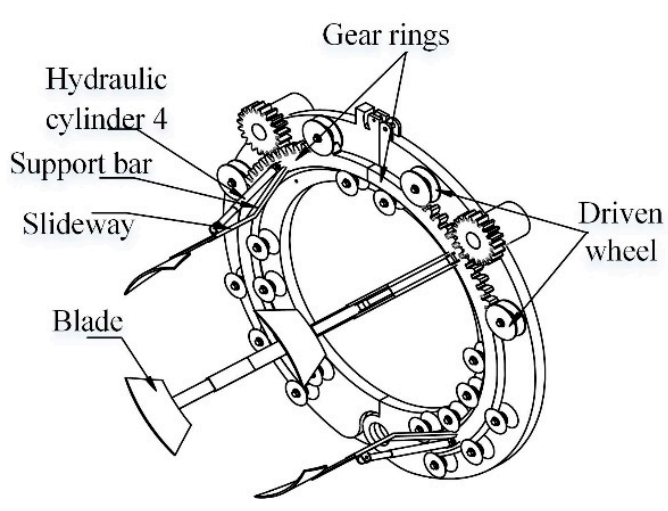

(D)

Figure 1. 3D model plan of marine steel pile cleaning robot, view (A and B), (C) The frame (D) The gears and the scraping tools.

The cleaning robot can also be operated underwater. The range of cleaning robot operations is $\pm 15 \mathrm{~m}$ about sea level. Marine fouling needs to be cleaned to protect against corrosion in the area where marine steel piles are located. At present, the cleaning robot can clean the marine steel pile with a diameter of $1 \mathrm{~m}$. Rotation speed range is 10 to $20^{\circ} / \mathrm{min}$. The cleaning robot moves up and down along the steel pile with a speed range from $1 \mathrm{~m} / 20 \mathrm{~min}$ to $1 \mathrm{~m} / 30 \mathrm{~min}$. The scraping tool material is Alloy Tool Steel, ISO 210Cr12, and the frame work material is aluminum alloy to reduce the overall weight of the robot.

After the cleaning robot is installed, with crane ship, to hug the steel pile, it can be operated automatically to clean the steel piles. When starting to install the cleaning robot so that it is hugging the steel pile, it needs cooperation of a crane ship and manual assistance. The the cleaning robot holds the frame stably with clamps, and it can clean the steel piles automatically with scraping tools vertically. The gears rotate at a certain angle, after the vertical cleaning, and continue to repeat vertical cleaning until whole surface is finished. The lower set of clamps release and three hydraulic cylinders 1 and 2 extend at the same time. When the hydraulic cylinder is extended to the limit, the lower set of clamps lock. Then, the upper set of clamps release, three hydraulic cylinder 1 and 2 draw back to the limit, and the upper set of clamps lock. At this time, the cleaning robot completes the downward movement and moves to a new position, which can clean up the new surface as above.

\section{Barnacle Geometric Model and Cleaning Methods}

In order to analyze the effect of the barnacle on the vortex-induced vibration of the cylinder, a model of a barnacle was created by Jadidi [25], which attached to the cylinder surface. This model was a trapezoidal cross section. The barnacle idealized model is as shown in Figure 2. The trapezoidal 
mound is used to represent the calcareous shell of the barnacle and the bottom layer represents the viscoelastic cement, which attach the barnacle to the rough substrate.

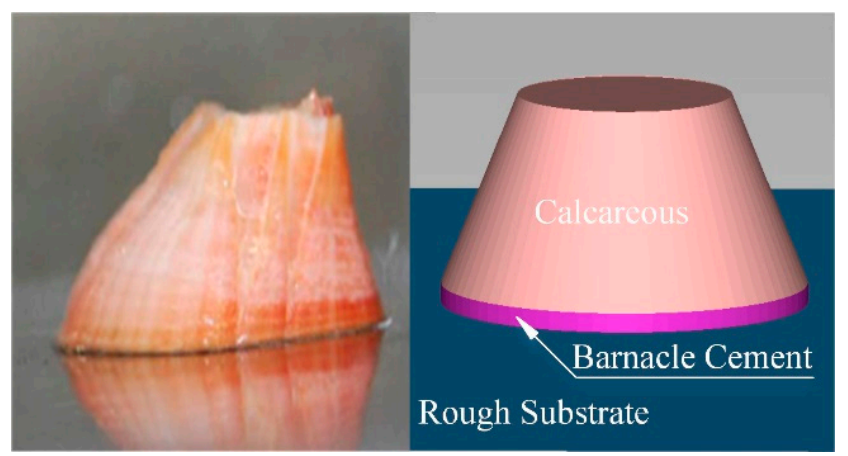

Figure 2. 3D model of barnacle.

The bottom diameter of the geometrical model is $d_{1}$, the top diameter is $d_{2}=7 d_{1} / 12$, the average height of one-year-old barnacle is, $h_{1}=5 d_{1} / 12$, and the height of cement layer is, $h_{2}=d_{1} / 24$, as shown in Figure 3. The parameters in Figure 3 are also shown in Appendix A.

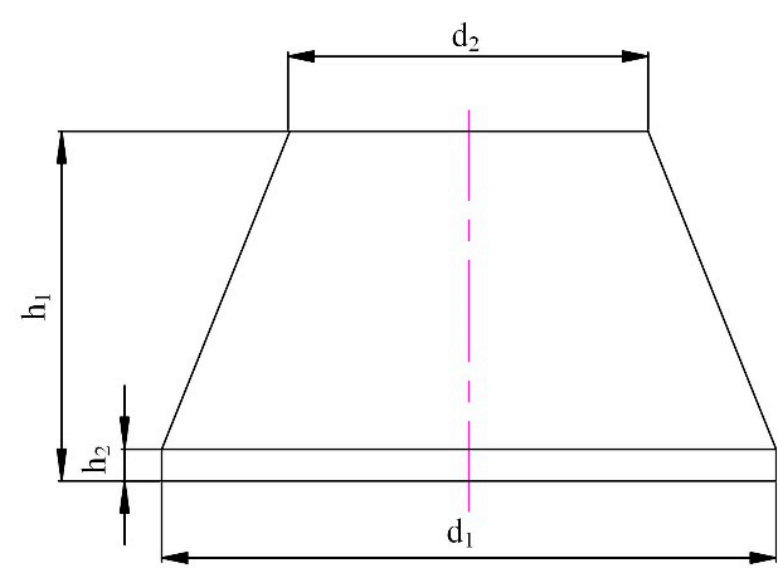

Figure 3. Barnacle geometrical model and dimensions.

The size/diameter of barnacles range from 8 to $43 \mathrm{~mm}$ [26]. The barnacle used was Balanomorpha genus, in particular, the Semibalanus balanoides (previous name Balanus balanoides). The S. balanoids is a sessile barnacle that attaches to hard substrates. This species has a highly synchronized settlement. The diameter can be measured and has a certain representativeness $[27,28]$. The adhesion force increased monotonously with the area and time of barnacle attachment. And and Walker [27,28] presented the relationship between barnacle size and adhesion, and concluded the adhesion strength of adult barnacles was $\mathrm{P}=9.252 \times 10^{5} \mathrm{~N} / \mathrm{m}^{2}$. The relation between the adhesion and barnacle diameter is as shown in Figure 4.

The Peel Zone method was proposed by Pesika $[29,30]$ to calculate the cutting force in barnacle cleaning. This paper proposed a method of cleaning barnacles based on the right angle cutting method and the Peel Zone method, namely scraping means. The scraping process of barnacles can be divided into two stages—cut-in stage A and peeling stage B-as shown in Figure 5. 


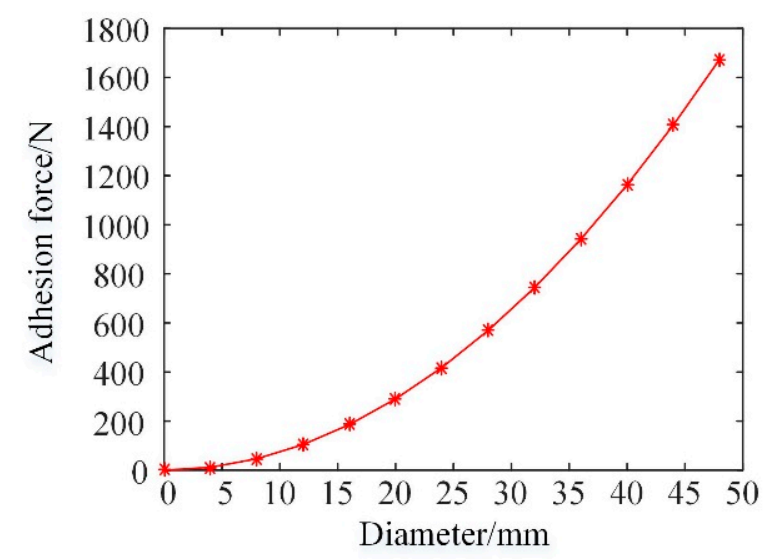

Figure 4. Adhesion of different barnacles with different diameters.

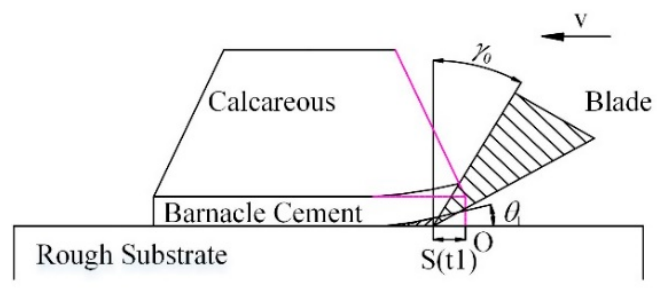

(A)

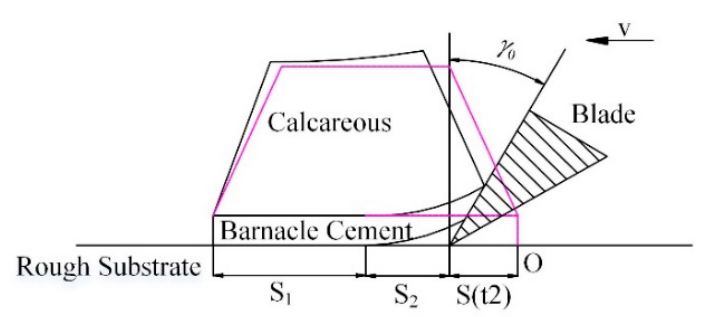

(B)

Figure 5. Schematic picture of removing the barnacle process.(A) Cut-in stage (B) Peeling stage.

The cut-in stage is as shown in Figure 5A. The blade with a rake angle of $\gamma_{0}$ moves towards the barnacle with a certain speed, when the blade cuts into the cement by $\mathrm{S}(\mathrm{t} 1)$ at $\mathrm{t} 1$, the rake face of the blade contacts the calcareous shell and produces a peel angle $\theta_{1}$.

The peeling stage, $B$, is as shown in Figure 5B. The blade further moves to $S(t 2)$ at $t 2$, whereby the peeling-produced cement damage happens. The calcareous shell bears the normal and tangential forces produced by the rake face of the blade in this stage. The normal force of the rake face is the main force for peeling, which causes the calcareous shell to be deformed and gradually lifted up. At this moment, $t 2$, the remaining adhesion length is $S_{1}$, the Peel Zone length is $S_{2}$, and $d_{1}=S_{1}+S_{2}+S(t 2)$. The theoretical peel angles is at the range about $0^{\circ}<\theta \leq 90^{\circ}$. After $t 2$, the resultant force of adhesion and friction decreases, until the barnacle is peeled off the substrate completely.

\section{Force Modeling}

Barnacles were tightly attached to rigid substrates with their cement. It was very difficult to clean up because of the calcareous shell tightly attached to the substrate and cement. In this paper, a scraping means was presented to analyze the cutting force on the surface of the barnacle. This method used the right angle cutting theory and the Peel Zone method used by Pesika $[29,30]$. The process of cleaning up the barnacle can be divided into two stages, as shown in Figure 5.

The parameters in the formula are shown in Appendix A.

Assume that: (1) The cutting tip of the blade is fully sharp; and (2) there is no friction on the flank face $[31,32]$. The cutting force $F$ on the rake face can be decomposed into two components (the normal force $F_{n}$ and the tangential friction force $F_{t}$ ), the calcareous shell is mainly deformed by the normal force $F_{n}$, and $F_{n}$ can be decomposed into $F_{n x}$ and $F_{n y}$, as shown in Figure 6 and

$$
\mathrm{F}_{\mathrm{n}}^{2}=\mathrm{F}_{\mathrm{nx}}{ }^{2}+\mathrm{F}_{\mathrm{ny}}{ }^{2}
$$




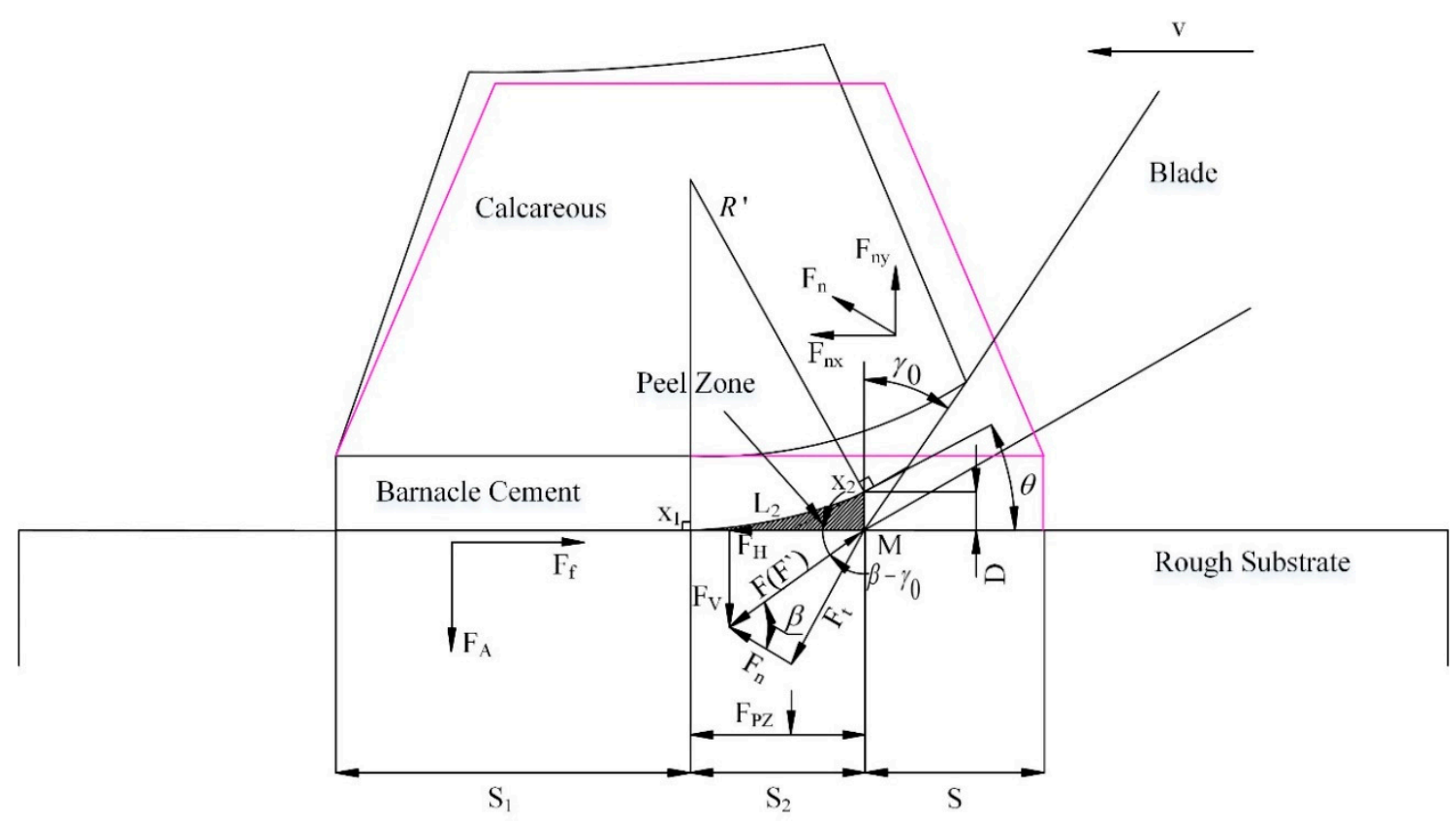

Figure 6. Force analysis in the peeling stage.

$\mathrm{F}^{\prime}$ is the counterforce of $\mathrm{F}$. The counterforce $\mathrm{F}^{\prime}$ can be decomposed into $\mathrm{F}_{\mathrm{H}}$ and $\mathrm{F}_{\mathrm{V}}$, in horizontal and vertical directions, respectively, and $\mathrm{F}_{\mathrm{H}}$ can be expressed as:

$$
\begin{gathered}
F_{H}=\frac{F_{n} \cos \left(\beta-\gamma_{0}\right)}{\cos \beta}, \\
F_{H}=\frac{\sqrt{F_{n x}^{2}+F_{n y}^{2}} \cos \left(\beta-\gamma_{0}\right)}{\cos \beta},
\end{gathered}
$$

where the angle $\beta$ between $F$ and Fn is the friction angle. $\gamma_{0}$ is the fake angle of the blade. The angle between $\mathrm{F}^{\prime}$ and $\mathrm{F}_{\mathrm{H}}$ is $\beta-\gamma_{0}$.

The barnacle bottom area can be divided into three zones: divided zone, peeling zone and adhesion zone, as shown in Figure 7. The following relations applies:

$$
\left\{\begin{array}{l}
F_{n x}=F_{f} \\
F_{n y}=F_{A}+F_{P Z}
\end{array},\right.
$$

where $F_{A}$ is the adhesion force in the adhesion zone, $F_{P Z}$ is the peeling force in the peel zone, and $F_{f}$ is the horizontal friction force and can be calculated individually. 


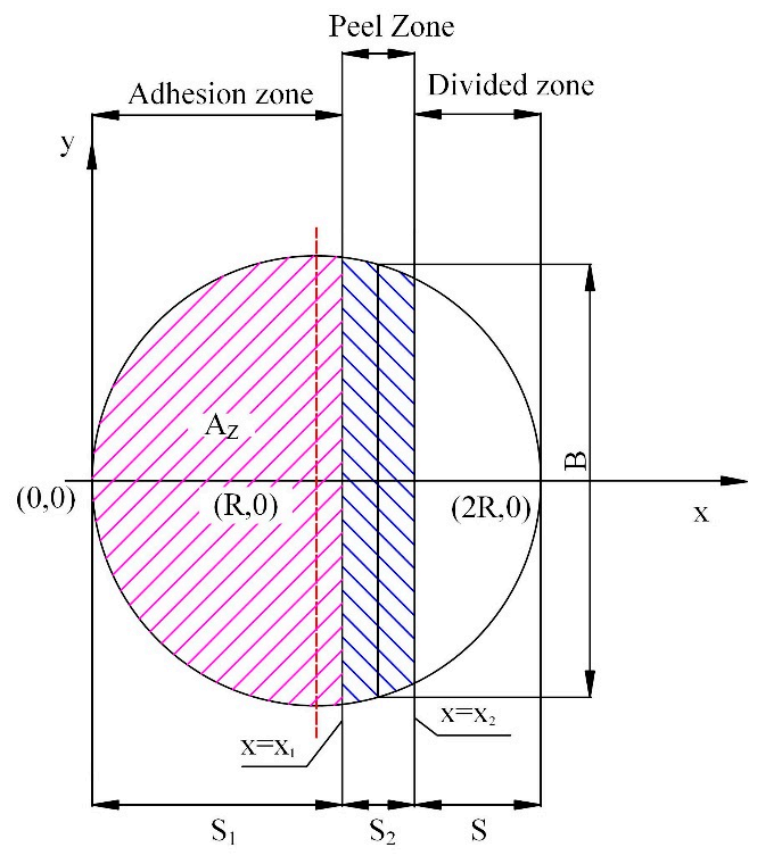

Figure 7. Zones definitions for the barnacle scraping.

\subsection{Calculation of $F_{P Z}$}

The normal force $F_{n}$ on the rake face acts on the calcareous shell and make it deformed. We assume that the trapezoidal bottom cross section deformation of the calcareous shell is actually a circular arc, the cement deformation changes with the calcareous shell, the bottom surface is also circular arc with a radius of $R^{\prime}$. We assume that the bottom surface keeps the same arc when the cement is peeled off, and $L_{2}$ is the arc length between $x_{1}$ and $x_{2}$. When $\theta$ is smaller, $L_{2}=R^{\prime} \theta \approx S_{2}$. The area is the Peel Zone, which is surrounded by points $x_{1}, x_{2}$, and $M$. The cement starts to scrape off the substrate at $x_{1}$. The last fiber of cement scrapes off the substrate at $x_{2}$, which is the critical point. $M$ is the critical point at which the last fiber of the cement is removed by blade tip. The $\theta$ is the peel angle which is between $x_{1}$ and $x_{2}$. The relationship according to the formula between the radius of curvature, $R^{\prime}$, and the peel angle, $\theta$, is $\mathrm{R}^{\prime}=4215 \times \theta^{-1.35}$ [30]. The B represents the width of the Peel Zone (as shown in Figure 7) between $x_{1}$ and $x_{2}$, which is $B=2 \sqrt{R^{2}-(R-S)^{2}}$. The adhesion force of the Peel Zone is written as [30]:

$$
F_{P Z}=\frac{A \sqrt{R^{\prime}\left(R^{2}-(R-S)^{2}\right)}}{8 \sqrt{2} D^{\frac{5}{2}}},
$$

A represents the Hamaker constant and D is represents the surface gap.

We know that the gecko spatula pad is made of $\beta$-keratin [29], that is a certain protein. In addition, the majority of barnacle cement is made of multi-protein complex [26]. Their adhesion mechanism is almost the same, which is caused by the intermolecular interactions $[26,29,30]$. The size of the gecko spatula pad and barnacle cement is of equal magnitude. Due to the similar properties mentioned, we make some similar assumptions to the gecko spatula pad to ensure that formulas of the Peel Zone can be calculated in this paper.

\subsection{Calculation of $F_{A}$ and $F_{f}$}

$\mathrm{A}_{\mathrm{Z}}$ is the area of the adhesion zone, which is shown Figure 7:

$$
A_{Z}=2 \int_{0}^{x_{1}} \sqrt{R^{2}-(X-R)^{2}} d X
$$


with $\mathrm{R}=0.012 \mathrm{~m}$, where $\mathrm{S}_{1}=\mathrm{d}_{1}-\mathrm{S}_{2}-\mathrm{S}$ and $\mathrm{S}_{2} \approx \mathrm{R}^{\prime} \theta$. The adult barnacle's adhesion strength is $\mathrm{P}=9.252 \times 10^{5} \mathrm{~N} / \mathrm{m}^{2}[27,28]$. Assuming that all barnacles to be removed are adult barnacles, the remaining adhesion force $\mathrm{F}_{\mathrm{A}}$ can be written as:

$$
\mathrm{F}_{\mathrm{A}}=\mathrm{P} \times\left(\frac{9 \pi}{125000}+\frac{9 \arcsin \left(\frac{250\left(2 \mathrm{R}-\mathrm{R}^{\prime} \theta-S\right)}{3}-1\right)}{62500}+\sqrt{\frac{9}{62500}-\left(\left(2 \mathrm{R}-\mathrm{R}^{\prime} \theta-\mathrm{S}\right)-\frac{3}{250}\right)^{2}} \times\left(\left(2 \mathrm{R}-\mathrm{R}^{\prime} \theta-\mathrm{S}\right)-\frac{3}{250}\right)\right),
$$

Substituting Equations (5) and (7) into (4), $\mathrm{F}_{\text {ny }}$ can be rewritten as:

$$
\begin{aligned}
F_{n y}= & P \times \\
& \left(\frac{9 \pi}{125000}+\frac{9 \arcsin \left(\frac{250\left(2 R-R^{\prime} \theta-S\right)}{3}-1\right)}{62500}+\right. \\
& \left.\left.\sqrt{\frac{9}{62500}-\left(\left(2 R-R^{\prime} \theta-S\right)-\frac{3}{250}\right)^{2}} \times\left(\left(2 R-R^{\prime} \theta-S\right)-\frac{3}{250}\right)\right)\right]+\left(\frac{A \cdot 2 \sqrt{R^{2}-(R-S)^{2}} \cdot\left(R^{\prime}\right)^{\frac{1}{2}}}{16 \sqrt{2} D^{\frac{5}{2}}}\right)
\end{aligned}
$$

$\mathrm{F}_{\mathrm{nx}}$ in the horizontal direction can be expressed as [30]:

$$
\mathrm{F}_{\mathrm{nx}}=\mathrm{F}_{\mathrm{f}}=\mu \times \mathrm{P} \times\left(\frac{9 \pi}{125000}+\frac{9 \arcsin \left(\frac{250\left(2 \mathrm{R}-\mathrm{R}^{\prime} \theta-\mathrm{S}\right)}{3}-1\right)}{62500}+\sqrt{\frac{9}{62500}-\left(\left(2 \mathrm{R}-\mathrm{R}^{\prime} \theta-\mathrm{S}\right)-\frac{3}{250}\right)^{2}} \times\left(\left(2 \mathrm{R}-\mathrm{R}^{\prime} \theta-\mathrm{S}\right)-\frac{3}{250}\right)\right),
$$

where $\mu$ is the friction coefficient between substrate and cement.

For smooth substrates, because there is no $F_{\mathrm{f}}$ and $F_{n x}$, through the trigonometric relationship $\mathrm{F}_{\mathrm{n}}=\mathrm{F}_{\mathrm{ny}} / \sin \gamma_{0}$, the cutting force can be expressed as $\mathrm{F}_{\mathrm{H}}$.

$$
\begin{gathered}
\mathrm{F}^{\prime}{ }_{\mathrm{H}}=\frac{\mathrm{F}_{\mathrm{ny}} \cos \left(\beta-\gamma_{0}\right)}{\cos \beta \sin \gamma_{0}}, \\
\mathrm{~F}_{\mathrm{H}}=\frac{\cos \left(\beta-\gamma_{0}\right)}{\cos \beta \sin \gamma_{0}}\left\{\left[\mathrm{P} \times\left(\frac{9 \pi}{125000}+\frac{9 \arcsin \left(\frac{250\left(2 R-R^{\prime} \theta-S\right)}{3}-1\right)}{62500}+\sqrt{\frac{9}{62500}-\left(\left(2 R-R^{\prime} \theta-S\right)-\frac{3}{250}\right)^{2}} \times\left(\left(2 \mathrm{R}-\mathrm{R}^{\prime} \theta-\mathrm{S}\right)-\frac{3}{250}\right)\right)\right]+\left(\frac{\mathrm{A} \cdot 2 \sqrt{\mathrm{R}^{2}-(\mathrm{R}-\mathrm{S})^{2}} \cdot\left(\mathrm{R}^{\prime}\right) \frac{1}{2}}{16 \sqrt{2} \frac{5}{2}}\right)\right\},
\end{gathered}
$$

For rough substrates, there is $F_{f}=F_{n x}$, thus the cutting force can be expressed as $F_{H}$.

$$
F_{H}=\frac{\sqrt{F_{n x}^{2}+F_{n y}^{2}} \cos \left(\beta-\gamma_{0}\right)}{\cos \beta}
$$

\subsection{Effect of Friction}

A typical curve is shown in the Figure 8, showing a 3D image of cutting force vs. displacement. The cutting force $\mathrm{F}_{\mathrm{H}}$ can also be drawn as a $3 \mathrm{D}$ picture, which is about the influence of rake angle. The rake angle of blade has a great influence on the cutting force. Increasing the rake angle can greatly decrease the cutting force in $\left(0,45^{\circ}\right)$, and the trend is relatively gentle in $\left(45-90^{\circ}\right)$. Considering the cutting force and the design of the scraping tools, the rake angle can be compromised. The blade rake angle could be recommended to $\left[30^{\circ}, 60^{\circ}\right]$. 


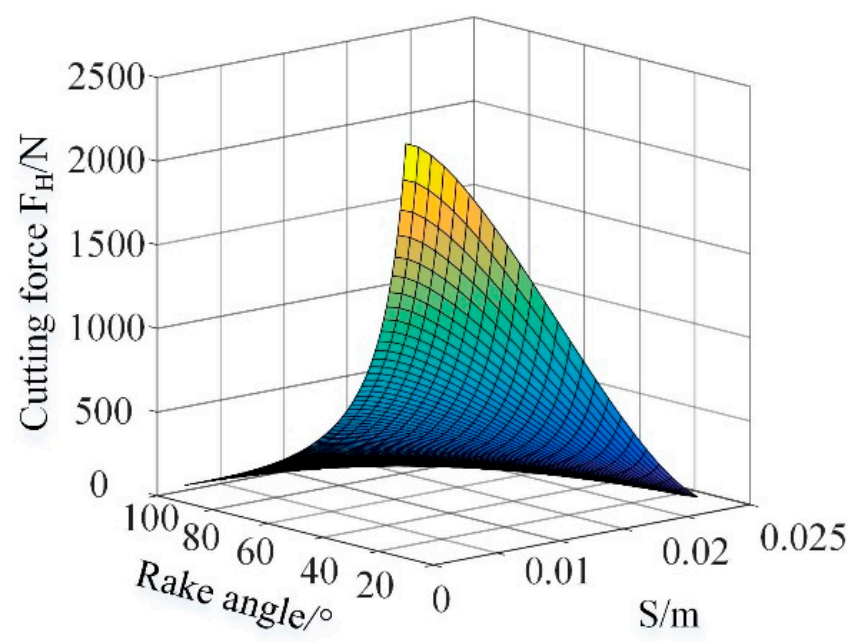

Figure 8. 3D picture of the cutting force $\mathrm{F}_{\mathrm{H}}$.

Among $\left[30^{\circ}, 60^{\circ}\right]$, we select $45^{\circ}$ and $60^{\circ}$ as examples. In the process of removing attached barnacles, the surface roughness of the substrate is considered to play a significant role in the scraping behavior. In nature, the smooth surface does not exist completely, and even highly polished surfaces are rough. The surface roughness shows a significant effect. Assume that the surface roughness changes monotonically with the relative friction coefficient under dry friction. In order to analyze the effect of relative friction coefficient on the cutting force in the process of removing barnacles, in the case of the blade rake angle of $45^{\circ}$ and $60^{\circ}$, according to the Formulas (10) and (12), we drew a 3D plot of rake angles $45^{\circ}$ and $60^{\circ}$, different friction coefficients, and displacement vs. horizontal cutting force, as shown in Figure 9.

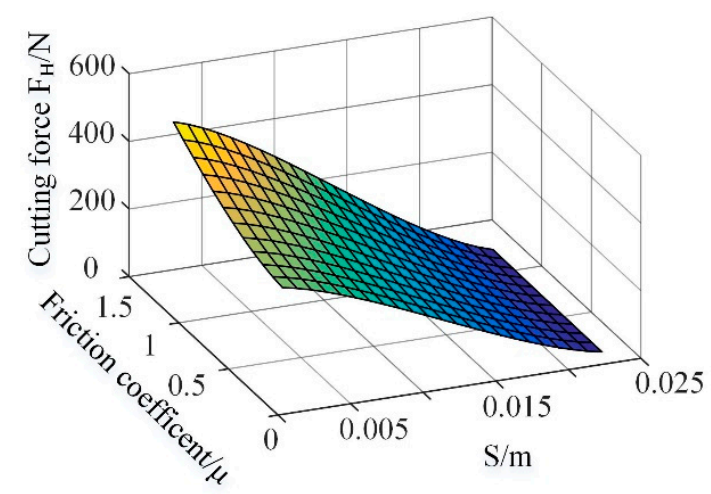

(a)

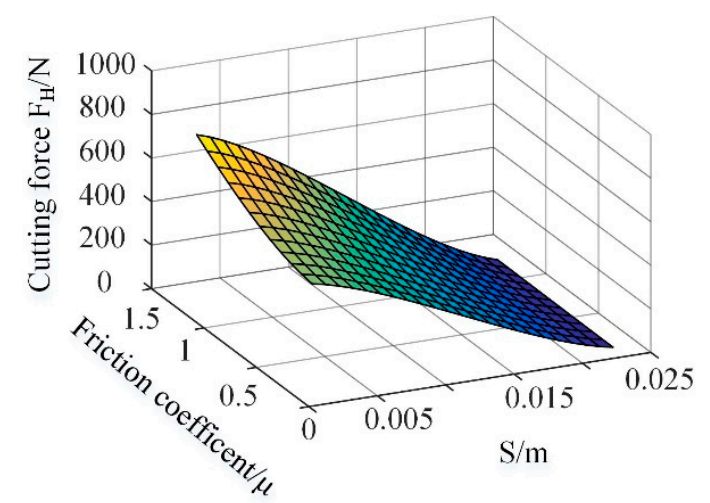

(b)

Figure 9. Detailed analysis of the barnacle. (a) $60^{\circ}$ blade rake (b) $45^{\circ}$ blade rake.

It is found that the cutting force $\mathrm{F}_{\mathrm{H}}$ increases with the increase monotonically with friction coefficient, and a larger friction coefficient corresponds to a greater amplitude of cutting force. At the same time, we also made contrast curves on smooth and rough substrates at rake angles $45^{\circ}$ and $60^{\circ}$, as shown in Figure 10. We can see straight away that the horizontal cutting force on the rough surface is much larger than that on the relatively smooth one at the same blade rake angle. 


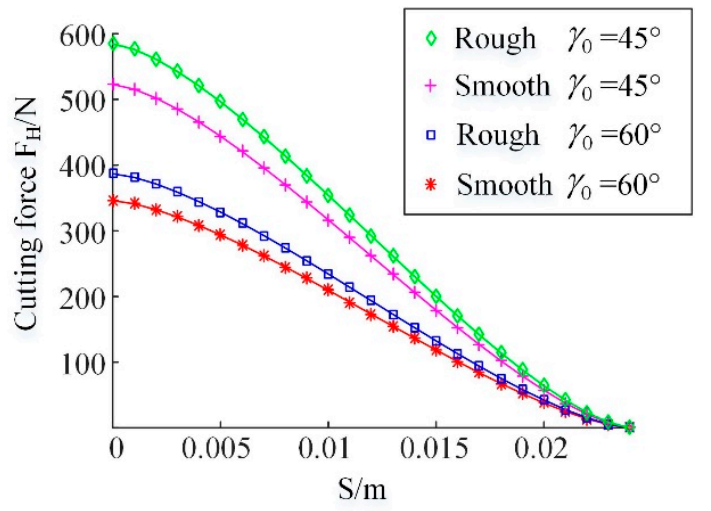

Figure 10. The cutting force of $45^{\circ}$ and $60^{\circ}$ blade rake angles vs. smooth and rough surfaces of the substrate.

\section{Simulation and Results}

In order to study the data and validation results of the mathematical model on smooth and rough substrates, we chose $60^{\circ}$ and $45^{\circ}$, respectively, to represent different blade rake angles. Therefore, the difference in results can be more intuitively presented in different rake angles. We established 3D finite element models in Hypermesh, as shown in Figure 11. The diameter of barnacle was $\mathrm{d} 1=0.024 \mathrm{~m}$. The size of height, cement thickness, and top can be drawn according to Figure 3. The blade rake angles were $60^{\circ}$ and $45^{\circ}$, respectively. The velocity of blade wass set as $0.7 \mathrm{~m} / \mathrm{s}$. The blade, barnacle shell, and cement were set as a solid element, but the substrate was set as the shell element to facilitate convergence of the results.

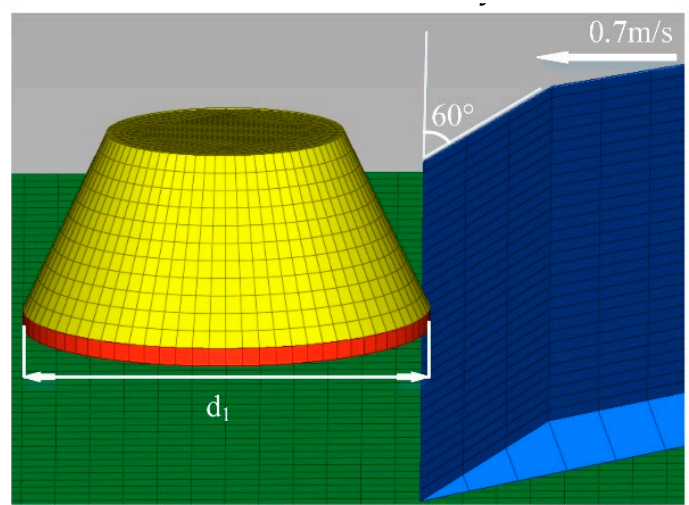

(a)

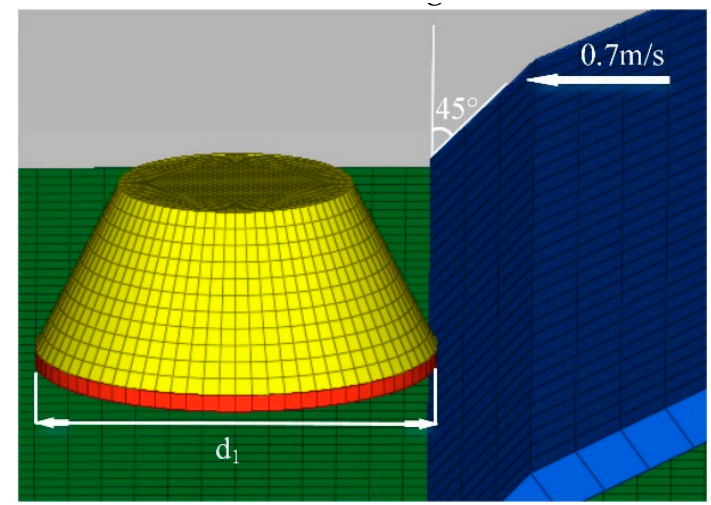

(b)

Figure 11. The simulation diagram of a barnacle. (a) $60^{\circ}$ blade rake simulation (b) $45^{\circ}$ blade rake simulation.

The failure contact command was set between the cement and substrate; The no failure contact command was set among the calcareous shell, cement, and blade. The blade and substrate was set as elastic material with density $\rho=7.93 \times 10^{3} \mathrm{~kg} / \mathrm{m}^{3}$, the bulk modulus was $\mathrm{K}=1.95 \times 10^{5} \mathrm{MPa}$, the Poisson's ratio was $\gamma=0.247$. The calcareous shell was set as plastic material with density $\rho=2.6 \times 103 \mathrm{~kg} / \mathrm{m}^{3}$, the bulk modulus was $\mathrm{K}=5 \times 10^{4} \mathrm{Mpa}$, the Poisson's ratio was $\gamma=0.3$; the cement was set as viscoelastic material with density $\rho=1.19 \times 10^{3} \mathrm{~kg} / \mathrm{m} 3$, bulk modulus was $\mathrm{K}=100 \mathrm{MPa}$. The whole 3D finite element model was meshed with 12,162 units and 15,405 nodes. The whole 3D finite element model was set to four couple groups in the contact system. The bottom substrate was fixed in six degrees of freedom and the velocity of the blade was set as $0.7 \mathrm{~m} / \mathrm{s}$ in the $x$ negative direction.

The results of horizontal cutting forces $\mathrm{F}_{\mathrm{H}}$ of the simulation and analytical curves are drawn in Figure 12 with regard of the blade displacement. When the blade rake is $60^{\circ}$, the results of the 
analytical and simulation smooth and rough curves of the cutting forces, $\mathrm{F}_{\mathrm{H}}$, are drawn in Figure 12a. The trends of smooth simulations agree with the analytical curve. Both smooth substrate curves of the cutting force, $\mathrm{F}_{\mathrm{H}}$, intersect at three points- $\mathrm{A}, \mathrm{B}$ and $\mathrm{C}$. The relative average error between both curves is less than $10 \%$. Although the trends of analytical rough curves agree with the simulations, it is not good as smooth curves. Both rough substrate curves of the cutting force, $\mathrm{F}_{\mathrm{H}}$, intersect at the point of D only. The relative average error between both curves are less than $20 \%$. When the blade rake is $45^{\circ}$, the results of the analytical and simulation smooth and rough curve of forces $\mathrm{F}_{\mathrm{H}}$ are drawn in Figure 12b. The trends of the smooth simulations agree with the analytical curve also. Both smooth substrate curves of force $\mathrm{F}_{\mathrm{H}}$ intersect at three points-E, F and G. Both rough substrate curves of force $\mathrm{F}_{\mathrm{H}}$ intersect at three points also- $-\mathrm{H}$, I and J. The relative average errors between smooth and rough curves are less than $10 \%$. Overall, the relative average error is less than $15 \%$. The average error between both results is because of the assumption of the mathematical model. The error is also related to meshing the model, the number of units, and the blade speed.

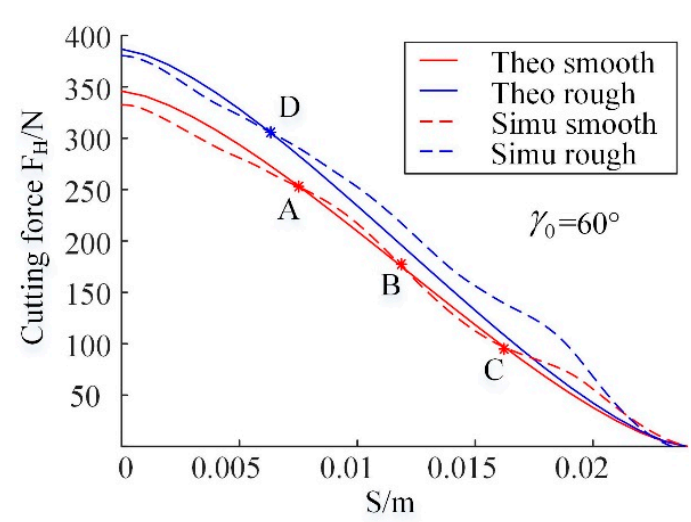

(a) $60^{\circ}$ blade rake simulation

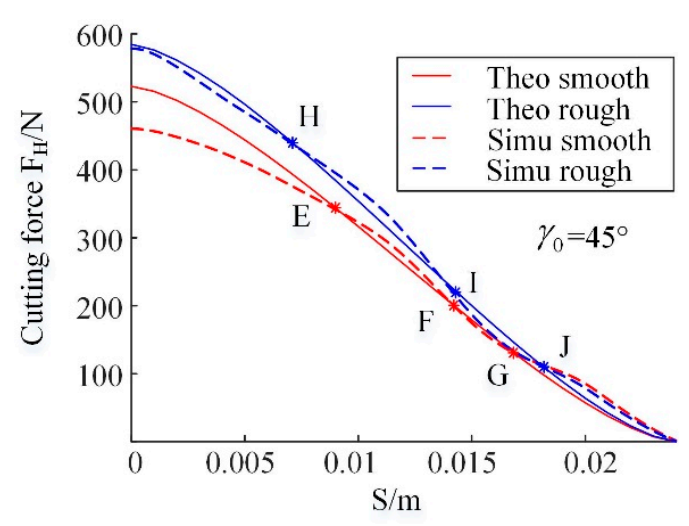

(b) $45^{\circ}$ blade rake simulation

Figure 12. Comparison of analytical and simulation results of $\mathrm{F}_{\mathrm{H}}$.

\section{Conclusions}

In this paper, a marine steel pile cleaning robot is designed to analyze the process of removing barnacles attached to a rough substrate. In addition, the mathematical model of cutting force is put forward for the barnacle scraping process, which is based on the right angle cutting theory and the Peel Zone method. Based on the verification, the following conclusions can be obtained:

(1) Through the finite element simulation, the mathematical analysis model is verified, and the verification results show that the relative average error of the mathematical model is less than $15 \%$. During the operation of barnacle scraping, the mechanical analysis process can be presented to estimate the horizontal cutting force in order to optimize the angle of the scraping blade for the cleaning robot design.

(2) During the scraping process, the blade rake angle and substrate roughness have a big effect on the horizontal cutting force. The blade rake angle could be recommended to $\left[30^{\circ}, 60^{\circ}\right]$. It could be seen that the smaller the blade rake angle, the greater the horizontal cutting force needed to clean up the barnacles, Additionally, the rougher the substrate is, the greater the horizontal cutting force required. Finally, it is recommended that a $60^{\circ}$ blade rake angle is more suitable for the cleaning robot design.

In the next stage, further research is required to select the suitable conditions and methods for the experiment. Firstly, the samples of marine fouling are multi-sample symbiosis on the actual marine steel piles. There is no single sample condition available for the experiment. The typical objects are required for experiment under the conditions of multi-sample symbiosis. Secondly, a statistics 
model is required to represent the actual condition of fouling and control the statistical parameters to approximate the actual situation. Finally, combining the cutting force model and statistic model, the total cutting force of the cleaning robot can be predicted and the results can be compared with the experiment. For example, we can select a steel plie with a typical barnacle distribution (with regard to sample concentration in unit area and sample size percentage), input these data into the statistics and cutting force combined model to predict the total cutting force, and compare with experiment results. With this comparison, the model can be further improved to minimize the prediction errors to support the clean robot design.

Author Contributions: Formal analysis, C.L. and G.W.; methodology, C.L.; writing—original draft preparation, C.L.; writing-review and editing, K.C., P.J., L.W. and X.W., validation, K.C., L.W. and P.J.; supervision L.W. and X.W.; funding acquisition, G.W. and F.Y. All authors have read and agreed to the published version of the manuscript.

Funding: This research was funded by National Key Research and Development Project (Grant No. 2018YFF01012900), National Natural Science Foundation of China (Grant No. 51779059, 51409058, 61633009, 51779064), China Postdoctoral Science Foundation (Grant No. 2020M670889), Fundamental Research Funds for the Central Universities (Grant No. 3072020CF0702, 3072020CFT0105), and the School Land Integration Development Project of Yantai (Grant No. 2019XDRHXMPT29).

Acknowledgments: The authors gratefully acknowledge the financial support from National Key Research and Development Project (Grant No. 2018YFF01012900), National Natural Science Foundation of China (Grant No. 51779059, 51409058, 61633009, 51779064), China Postdoctoral Science Foundation (Grant No. 2020M670889), Fundamental Research Funds for the Central Universities (Grant No. 3072020CF0702, 3072020CFT0105), and the School Land Integration Development Project of Yantai (Grant No. 2019XDRHXMPT29).

Conflicts of Interest: The authors declare no conflict of interest.

\section{Appendix A}

Table A1. The parameters in the formula.

\begin{tabular}{ccc}
\hline Symbol & Significance & Unit \\
\hline $\mathrm{d}_{1}$ & The bottom diameter of the barnacle geometrical model & $\mathrm{mm}$ \\
$\mathrm{d}_{2}$ & The top diameter of the barnacle geometrical model & $\mathrm{mm}$ \\
$\mathrm{h}_{1}$ & The average height of one-year-old barnacle & $\mathrm{mm}$ \\
$\mathrm{h}_{2}$ & The height of cement layer & $\mathrm{mm}$ \\
$\mathrm{F}$ & Cutting force & $\mathrm{N}$ \\
$\mathrm{F}_{\mathrm{n}}$ & Normal component force of $\mathrm{F}$ & $\mathrm{N}$ \\
$\mathrm{F}_{\mathrm{t}}$ & Tangential friction force & $\mathrm{N}$ \\
$\mathrm{F}_{\mathrm{n} x}$ & Horizontal component force of $\mathrm{F}_{\mathrm{n}}$ & $\mathrm{N}$ \\
$\mathrm{F}_{\mathrm{n}}$ & Vertical component force of $\mathrm{F}^{\prime}$ & $\mathrm{N}$ \\
$\mathrm{F}^{\prime}$ & Counterforce of $\mathrm{F}$ & $\mathrm{N}$ \\
$\mathrm{F}_{\mathrm{H}}$ & Horizontal component force of $\mathrm{F}^{\prime}(\mathrm{rough})$ & $\mathrm{N}$ \\
$\mathrm{F}_{\mathrm{H}}^{\prime}$ & Horizontal component force of $\mathrm{F}^{\prime}(\mathrm{smooth})$ & $\mathrm{N}$ \\
$\mathrm{F}_{\mathrm{V}}$ & Vertical component force of $\mathrm{F}^{\prime}$ & $\mathrm{N}$ \\
$\gamma_{0}$ & Fake angle of the blade & $\circ$ \\
$\beta$ & The angle between F and Fn & $\circ$ \\
$\beta_{-} \gamma_{0}$ & The angle between F' and $\mathrm{F}_{\mathrm{H}}$ & $\circ$ \\
$\mathrm{F}_{\mathrm{A}}$ & Adhesion force of barnacle & $\mathrm{N}$ \\
$\mathrm{F}_{\mathrm{PZ}}$ & Peeling force & $\mathrm{N}$ \\
$\mathrm{F}_{\mathrm{f}}$ & Horizontal friction force of barnacle & $\mathrm{N}$ \\
$\mathrm{A}_{\mathrm{Z}}$ & The area of the adhesion zone & $\mathrm{m}$ \\
$\mathrm{R}^{\prime}$ & Radius of calcareous shell circular arc & $\mathrm{m}$ \\
$\mathrm{L}_{2}$ & Arc length & $\mathrm{m}$ \\
$\mathrm{x}_{1}, \mathrm{x}_{2}$ & Point on arc length & $\mathrm{m}$ \\
$\theta$ & Peel angle & $\circ$ \\
$\mathrm{B}$ & Width of the Peel Zone & $\mathrm{m}$ \\
$\mathrm{A}$ & Hamaker constant & \\
$\mathrm{D}$ & Surface gap & $\mathrm{m}$ \\
$\mathrm{R}$ & Barnacle diameter & $\mathrm{N}$ \\
$\mathrm{P}$ & Barnacle's adhesion strength & Blade displacement \\
$\mathrm{S}$ & Friction coefficient between substrate and cement & \\
$\mu$ & & \\
\hline & & \\
\hline
\end{tabular}




\section{References}

1. Wei, S.C.; Xu, B.S.; Liang, X.B.; Wang, Y.J.; Liu, Y. Research on Corrosion-Resistance of High Velocity Arc Spray Coatings on Surface of Steel Structure in Splash Zone Environment. Mater. Sci. Forum 2011, 675-677, 1291-1294. [CrossRef]

2. Magin, C.M.; Cooper, S.P.; Brennan, A.B. Non-toxic antifouling strategies. Mater. Today 2010, $13,36-44$. [CrossRef]

3. Telegdi, J.; Trif, L.; Románszki, L. Smart anti-biofouling composite coatings for naval applications. Smart Compos. Coat. Membr. 2016, 123-155. [CrossRef]

4. Yebra, D.M.; Kiil, S.; Dam-Johansen, K. Antifouling technology-past, present and future steps towards efficient and environmentally friendly antifouling coatings. Prog. Org. Coat. 2004, 50, 75-104. [CrossRef]

5. Gao, H.B.; Chen, Q.; Wang, J.; Liu, B.Y.; Wan, Z.X.; Hou, B.R. Anticorrosion Technology Application of Petrolatum Tape and Covering (PTC) on Offshore Wind Farm. China Coat. 2013, 28, 39-43.

6. Gule, N.P.; Begum, N.M.; Klumperman, B. Advances in biofouling mitigation: A review. Crit. Rev. Environ. Sci. Technol. 2016, 46, 535-555. [CrossRef]

7. Jia, R.; Li, Y.; Al-Mahamedh, H.; Gu, T. Enhanced Biocide Treatments with D-amino Acid Mixtures against a Biofilm Consortium from a Water Cooling Tower. Front. Microbiol. 2017, 8, 1538. [CrossRef]

8. Rubio, D.; Casanueva, J.F.; Nebot, E. Assessment of the antifouling effect of five different treatment strategies on a seawater cooling system. Appl. Therm. Eng. 2015, 85, 124-134. [CrossRef]

9. Neilson, B.J.; Wall, C.B.; Mancini, F.T.; Gewecke, C.A. Herbivore biocontrol and manual removal successfully reduce invasive macroalgae on coral reefs. Peer] 2018, 6, 5332. [CrossRef]

10. Albitar, H.; Dandan, K.; Ananiev, A.; Kalaykov, I. Underwater Robotics: Surface Cleaning Technics, Adhesion and Locomotion Systems. Int. J. Adv. Robot. Syst. 2016, 13, 7. [CrossRef]

11. Eslamdoost, A.; Larsson, L.; Bensow, R. A pressure jump method for modeling waterjet/hull interaction. Ocean. Eng. 2014, 88, 120-130. [CrossRef]

12. Narewski, M. Hismar-Underwater Hull Inspection And Cleaning System As A Tool For Ship Propulsion System Performance Increase. J. Pol. CIMAC 2009, 4, 227-232.

13. Yamada, J.; Takiguchi, T.; Saito, A.; Odanaka, H.; Soyama, H.; Yamamoto, M. Removal of Oral Biofilm on an Implant Fixture by a Cavitating Jet. Implant Dent. 2017, 26, 904-910. [CrossRef] [PubMed]

14. Guo, S.; Khoo, B.C.; Teo, S.L.; Lee, H.P. The effect of cavitation bubbles on the removal of juvenile barnacles. Colloids Surf. B Biointerfaces 2013, 109, 219-227. [CrossRef]

15. Legg, M.; Yuecel, M.K.; de Carellan, I.G.; Kappatos, V.; Selcuk, C.; Gan, T.H. Acoustic methods for biofouling control: A review. Ocean Eng. 2015, 103, 237-247. [CrossRef]

16. Mazue, G.; Viennet, R.; Hihn, J.; Carpentier, L.; Albaina, I. Large-scale ultrasonic cleaning system: Design of a multi-transducer device for boat cleaning (20 kHz). Ultrason. Sonochem. 2010, 18, 895-900. [CrossRef] [PubMed]

17. Patil, J.S.; Kimoto, H.; Kimoto, T.; Saino, T. Ultraviolet radiation (UV-C): A potential tool for the control of biofouling on marine optical instruments. Biofouling 2007, 23, 215-230. [CrossRef]

18. Lopez-Galindo, C.; Casanueva, J.F.; Nebot, E. Efficacy of different antifouling treatments for seawater cooling systems. Biofouling 2010, 26, 923-930. [CrossRef]

19. Murakawa, M.; Takeuchi, S. Quantitative adhesion strength measurement of diamond coatings. Thin Solid Films 1989, 181, 443-450. [CrossRef]

20. Xie, Z.; Zhu, J. The effect of the vertical load on the scraping test. Thin Solid Films 1998, 315, $192-194$. [CrossRef]

21. Xie, Z.; Zhu, J.; Guo, W. The Scraping Test and Adhesion Measurements of Diamond and Nickel Electroless Coatings. Mater. Charact. 2000, 44, 347-352. [CrossRef]

22. Daitoku, T.; Utaka, Y. An effect of scraper shapes on detachment of solid adhered to cooling surface for formation of clathrate hydrate slurry. Heat Transfer. Asian Res. 2007, 36, 489-500. [CrossRef]

23. Matsumoto, K.; Akimoto, T.; Teraoka, Y. Study of scraping force of ice growing on cooling solid surface. Int. J. Refrig. 2010, 33, 419-427. [CrossRef]

24. Li, Y.; Li, M.; Utaka, Y.; Daitoku, T.; Ohkubo, H.; Yang, C. Scraping force characteristics of frost formed on vertical cooling surfaces having different structures and wettability. Int. J. Refrig. 2019, 101, 148-154. [CrossRef] 
25. Jadidi, P.; Zeinoddini, M.; Soltanpour, M.; Zandi, A.P.; Seif, M.S. Towards an understanding of marine fouling effects on VIV of circular cylinders: Aggregation effects. Ocean Eng. 2018, 147, 227-242. [CrossRef]

26. Crisp, D.J.; Bourget, E. Growth in Barnacles. Adv. Mar. Biol. 1985, 22, 199-244.

27. And, A.B.Y.; Walker, G. The Adhesion of the Barnacle, Balanus Balanoides, to Slate Surfaces. J. Mar. Biol. Assoc. UK 2009, 64, 147-156.

28. Smith, D.A.M.; Callow, D.J.A. Biological Adhesives, 1st ed.; Springer: Berlin, Germany, 2006; pp. $145-152$.

29. Pesika, N.S.; Tian, Y.; Zhao, B.; Rosenberg, K.; Zeng, H.; McGuiggan, P.; Autumn, K.; Israelachvili, J.N. Peel-zone model of tape peeling based on the gecko adhesive system. J. Adhes. 2007, 83, 383-401. [CrossRef]

30. Yu, T.; Noshir, P.; Hongbo, Z.; Kenny, R.; Boxin, Z.; Patricia, M.G.; Kellar, A.; Jacob, I. Adhesion and friction in gecko toe attachment and detachment. Proc. Natl. Acad. Sci. USA 2006, 103, 19320-19325.

31. Merchant, M.E. Mechanics of the Metal Cutting Process. I. Orthogonal Cutting and a Type 2 Chip. J. Appl. Phys. 1945, 16, 267-275. [CrossRef]

32. Merchant, M.E. Mechanics of the Metal Cutting Process. II. Plasticity Conditions in Orthogonal Cutting. J. Appl. Phys. 1945, 16, 318-324. [CrossRef]

(C) 2020 by the authors. Licensee MDPI, Basel, Switzerland. This article is an open access article distributed under the terms and conditions of the Creative Commons Attribution (CC BY) license (http://creativecommons.org/licenses/by/4.0/). 